\title{
Indication for SARS-CoV-2 serology: First month follow-up
}

\author{
Alix T Coste ${ }^{1}$, Katia Jaton ${ }^{1}$, Matthaios Papadimitriou-Olivgeris ${ }^{2,3}$, Antony Croxatto ${ }^{1 *}$ and Gilbert Greub $^{1,3 \# *}$ \\ ${ }^{1}$ Institute of Microbiology, Lausanne University Hospital and University of Lausanne, Lausanne, Switzerland \\ ${ }^{2}$ Service of Hospital Preventive Medicine, Lausanne University Hospital, Switzerland \\ ${ }^{3}$ Service of Infectious Diseases, Lausanne University Hospital, Switzerland \\ "These authors have contributed equally to the study
}

\begin{abstract}
SARS-CoV-2 detection is mainly performed by RT-PCR, but recently serological tests were made available. A first one-month follow-up of the SARS-CoV-2 serology records was performed in our laboratory to precise the diversity and proportion of the SARS-CoV-2 serology test clinical argument as a first hint to identify potential valid indications (meningoencephalitis, vasculitis, ...).
\end{abstract}

\section{Introduction}

A new coronavirus was discovered late in 2019 following an unusual number of pneumonia in the city of Wuhan in China. This virus was named SARS-CoV-2 and the disease was named Coronavirus Disease 2019 (CoVID-19) (https://www.who.int/news-room/detail/27-042020-who-timeline---covid-19). This pandemic arrived in Switzerland on $25^{\text {th }}$ February 2020 . On $18^{\text {th }}$ May 2020 , as many as 31,218 persons were documented with a SARS-CoV-2 infection causing 1956 deaths in Switzerland, whereas in Vaud county, where our university hospital is located, 5413 cases were documented with 420 deaths (www.coronadata.ch).

Detection of the SARS-CoV-2 was mainly performed by PCR on nasopharyngeal swab during the acute phase of the disease $[1,2]$. Recently, commercial serological tests were available allowing the determination of the serostatus of patient [3]. The SARS-CoV-2 serology was implemented and used for patient care since $14^{\text {th }}$ April 2020 in our laboratory of microbiology located at the "Centre Hospitalier Universitaire Vaudois" (CHUV).

Initially, only few indications were recognized by public health authorities (indications 1 to 3, Table 1), but we rapidly extended these indications to include the list detailed in Table 1. Our laboratory performed a prospective surveillance of the SARS-CoV-2 serologic test requested during the first 5 weeks, by specifically looking at rate of the different accepted indications. We also prospectively checked for a sudden increase in testing requests from a specific ward of our university hospital and/or from a tertiary hospital, a private clinic or a specific private practitioner. Finally, we also identified prospectively new possible indications.

The aims of this work were (i) to precise the diversity and proportion of argument for the SARS-CoV-2 serological test and (ii) to report any deviation of its usage as compared to the initial indications recognized by our public health authorities.

\section{Results and discussion}

From the $14^{\text {th }}$ April 2020 to $18^{\text {th }}$ May 2020, 686 SARS-CoV-2 serological tests were performed in our laboratory using the Epitope
Diagnostics IgG ELISA (San Diego, CA). Twenty-nine (4\%) were prescribed by private practitioners, $303(44 \%)$ by hospital-based physicians working in tertiary hospitals or clinics, and 354 (52\%) by physicians of our institution. These tests were performed on 602 patients, including 367 female subjects (61\%) from 0 to 89 years old, and 235 male persons (39\%) from 1 to 96 years old. On the 686 serological tests performed 159 were positive (23.2\%), 522 were negative (76.1\%), and five were undetermined (0.7\%). Among the 28 serologies prescribed by private practitioners, five were positive (18\%) and 23 were negative $(82 \%)$. For the 303 serologies requested by hospital-based physicians working in tertiary hospitals or clinics, 94 were positive (31\%), 205 were negative (68\%), and four were undetermined (1\%). Finally, for the 354 serological tests from clinicians working at CHUV, 59 were positive (17\%), 294 were negative $(83 \%)$ and one was undetermined $(<1 \%)$. Initially, we observed that tertiary hospital B sent more serology analyses than expected. They had specific directives in their hospital to systematically perform a SARS-CoV-2 RT-PCR screening and serology to any patient arriving at the hospital. This practice being not in accordance with the county directives, we notified this to the hospital B physicians. Then, starting from week three, we did not observe any specific prescription-related pattern (Figure 1).

Regarding the non-CHUV serological requests, we decided to focus only on the clinical information available on the laboratory request form. Only 22 (6.6\%) of 332 serological requests contained such information. Fourteen serological tests were performed for patients with indication $\mathrm{N}^{\circ} 1$ (SARS symptoms with $>2$ negative RT-PCR), one with indication $\mathrm{N}^{\circ} 2$ (discordant RT-PCR), one with indication $\mathrm{N}^{\circ} 4.4$ (vulnerable subjects: hypertension \& obesity), three with indication

${ }^{*}$ Correspondence to: Gilbert Greub, Institute of Microbiology, Lausanne University Hospital and University of Lausanne, Bugnon 48, CH-1011 Lausanne, Switzerland, Tel: +41(0)213144979; Fax: +41(0)213144060; E-mail: gilbert. greub@chuv.ch

Key words: SARS-CoV-2, serology, indications

Received: November 05, 2019; Accepted: November 24, 2020; Published: November 30, 2020 
Table 1. Clinical arguments of the CHUV SARS-CoV-2 serology requests

\begin{tabular}{|c|c|c|c|c|c|c|c|c|}
\hline \multirow[b]{2}{*}{ Indications } & \multicolumn{2}{|c|}{ Negative } & \multicolumn{2}{|c|}{ Positive } & \multicolumn{2}{|c|}{ Undetermined } & \multicolumn{2}{|c|}{ Total } \\
\hline & $\mathbf{n}$ & $\begin{array}{l}\% \text { of the } \\
\text { indication }\end{array}$ & $\mathbf{n}$ & $\begin{array}{l}\% \text { of the } \\
\text { indication }\end{array}$ & $\mathbf{n}$ & $\begin{array}{l}\% \text { of the } \\
\text { indication }\end{array}$ & $\mathbf{n}$ & $\begin{array}{c}\% \text { of the total } \\
\text { request }\end{array}$ \\
\hline 1- SARS symptoms with 2 negative RT-PCRs & 65 & 84.4 & 11 & 14.3 & 1 & 1.3 & 77 & 28 \\
\hline 2- Discordant RT-PCRs & 1 & 33.3 & 2 & 66.6 & & & 3 & 0.8 \\
\hline 3- Hospital hygiene concern & 7 & 87.5 & 1 & 12.5 & & & 8 & 2.2 \\
\hline 4- High-risk vulnerable patients & 160 & 91 & 16 & 9 & & & 176 & 49.8 \\
\hline 4.1- Transplantation & 7 & & 7 & & & & 14 & \\
\hline 4.2- Oncology & 61 & & 4 & & & & 65 & \\
\hline 4.3-Gynecological/obstetrical & 88 & & 4 & & & & 92 & \\
\hline 4.4- Hypertension and obesity & $\mathbf{0}$ & & $\mathbf{0}$ & & & & $\mathbf{0}$ & \\
\hline 4.5- Immunosuppression & 4 & & 1 & & & & 5 & \\
\hline 5- Specific clinical presentation & 23 & 71 & 9 & 29 & & & 32 & 9 \\
\hline 5.1- Dermatological & 13 & & 1 & & & & 14 & \\
\hline 5.2- Diarrhea & 1 & & $\mathbf{0}$ & & & & 1 & \\
\hline 5.3- Meningo-encephalitis & 2 & & $\mathbf{0}$ & & & & 2 & \\
\hline 5.4- Kawasaki syndrome & $\mathbf{0}$ & & 1 & & & & 1 & \\
\hline 5.5- Guillain-Barré syndrome & 5 & & 2 & & & & 7 & \\
\hline 5.6- Ophtalmologic & 2 & & $\mathbf{0}$ & & & & 2 & \\
\hline $\begin{array}{l}\text { 5.7- Others thromboembolic disease, fever, } \\
\text { myalgia... }\end{array}$ & o & & 5 & & & & 5 & \\
\hline 6- Other indications & 27 & 84 & 5 & 16 & & & 32 & 9 \\
\hline 6.1- Possible personal interest & 3 & & $\mathbf{0}$ & & & & 3 & \\
\hline 6.2- Clinical study & 2 & & 3 & & & & 5 & \\
\hline 6.3- Indication for RT-PCR and not serology & 4 & & $\mathbf{0}$ & & & & 4 & \\
\hline 6.4- Residual symptoms with no or neg PCR & 18 & & 2 & & & & 20 & \\
\hline 7- No valid argument - positive RT-PCR & 6 & 33.3 & 12 & 66.6 & & & 18 & 5 \\
\hline 8- No information & 5 & 62.5 & 3 & 37.5 & & & 8 & 2.2 \\
\hline $\begin{array}{l}\text { TOTAL } \\
\text { (\% of the total requests) }\end{array}$ & \multicolumn{2}{|c|}{$\begin{array}{l}n=294 \\
(83)\end{array}$} & \multicolumn{2}{|c|}{$\begin{array}{l}n=59 \\
(16.6)\end{array}$} & \multicolumn{2}{|c|}{$\begin{array}{l}n=1 \\
(0.4)\end{array}$} & \multicolumn{2}{|c|}{$\mathrm{n}=354$} \\
\hline
\end{tabular}

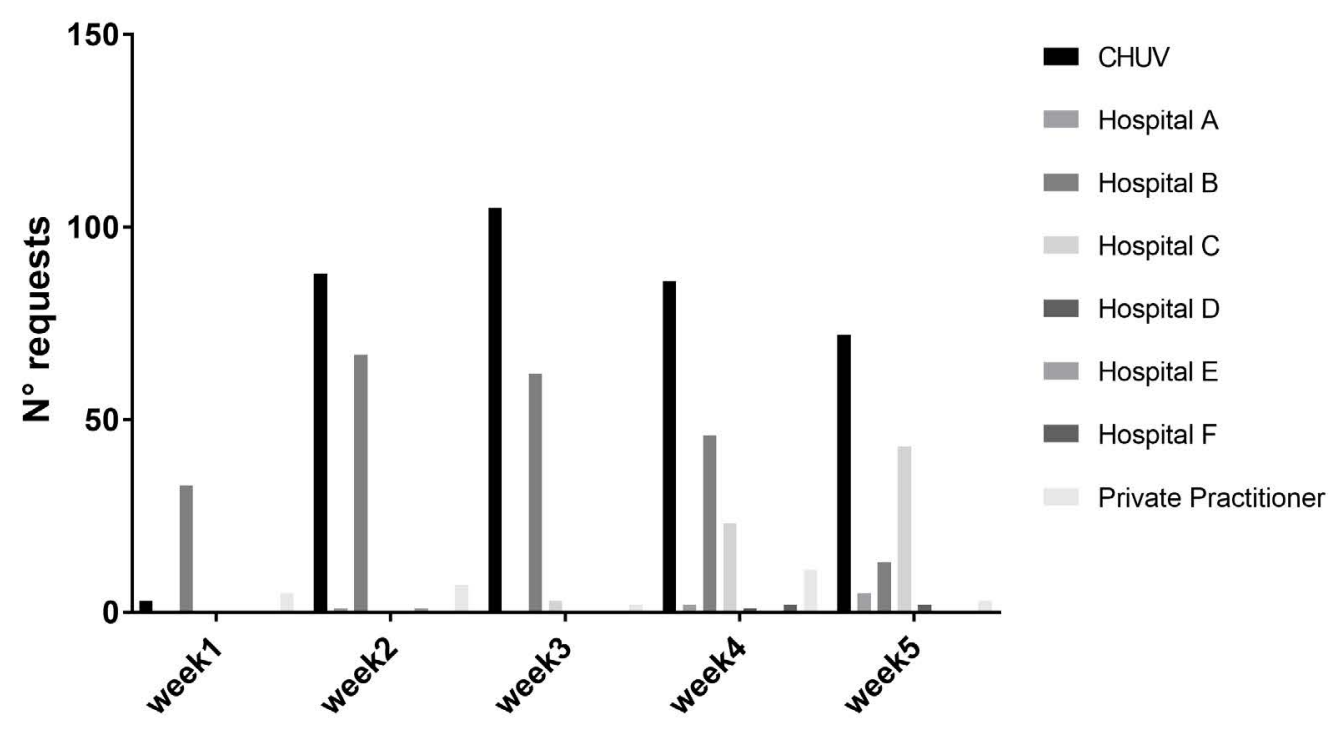

Figure 1. Evolution of the SARS-CoV-2 serology requests according medical center origin

$\mathrm{N}^{\circ} 5$ (specific clinical presentation) including one with Guillain-Barré syndrome, one with indication $\mathrm{N}^{\circ} 6.1$ (personal interest) and two with indication $\mathrm{N}^{\circ} 6.4$ (residual symptoms but who had no RT-PCR results available). Noteworthy, there was no indication of serology for 22 (6.6\%) of the 332 requested serologies, as they already had a positive SARS-CoV-2 RT-PCR, all coming from tertiary hospital B. This was due to the hospital $\mathrm{B}$ directive to systematically screen any incoming patient by RT-PCR and serology, to ideally increase the overall screening sensitivity. Noteworthy, the serology result can only be used to confirm an infection and not to assess the protection of the patient, since no clear relationship between the serostatus and the protection against a new infection by the SARS-CoV-2 was established. Therefore, the serology was useless for these 22 cases, since a positive RT-PCR is clearly sufficient to prove the infection.

The 354 CHUV requests correspond to 313 patients. Among those 313 patients, $54(17.2 \%)$ had a positive SARS-CoV-2 serology. 
A

All SARS-CoV-2 serology request from $\mathrm{CHUV}$ $(\mathrm{N}=354)$

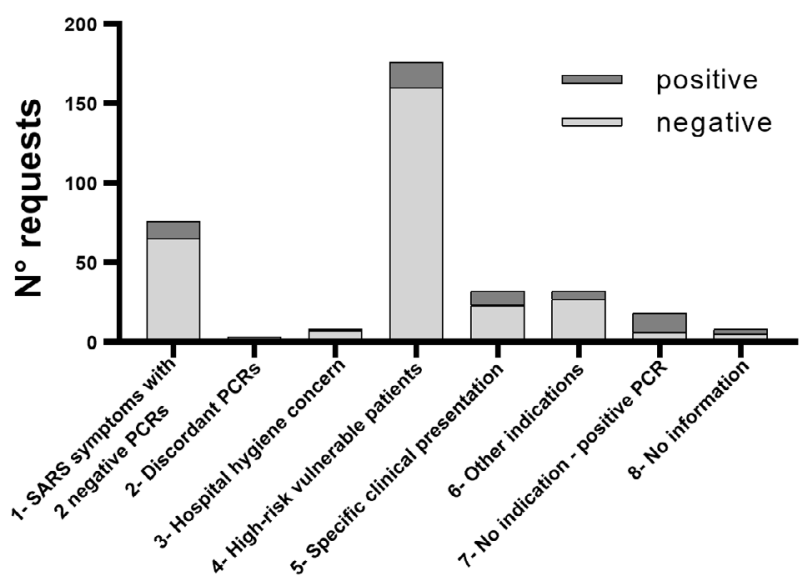

C

SARS-CoV-2 serology requests for Specific clinical presentation ( $N=32)$

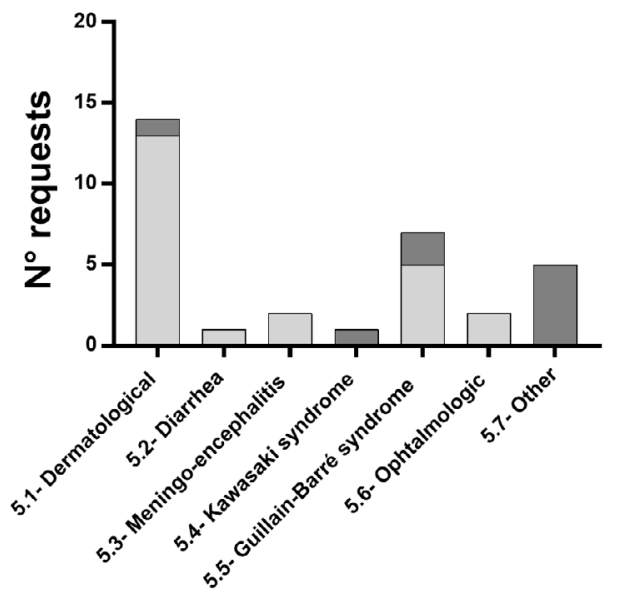

B SARS-CoV-2 serology requests for High-risk vulnerable patients $(\mathrm{N}=176)$

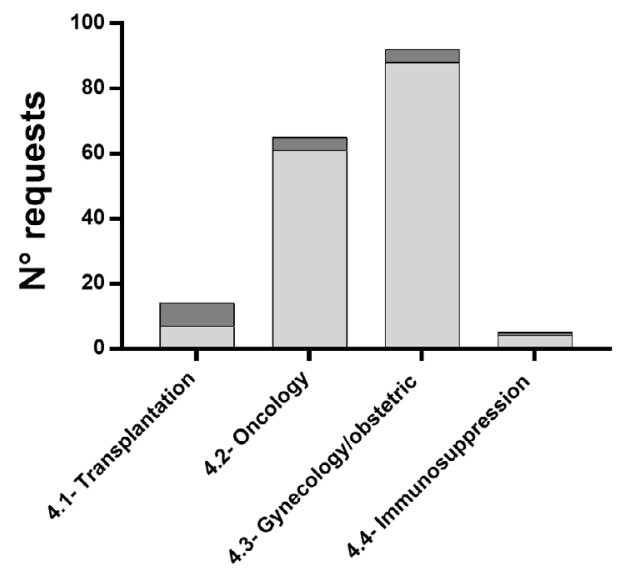

D SARS-CoV-2 serology requests for Other indications $(\mathbf{N}=32)$

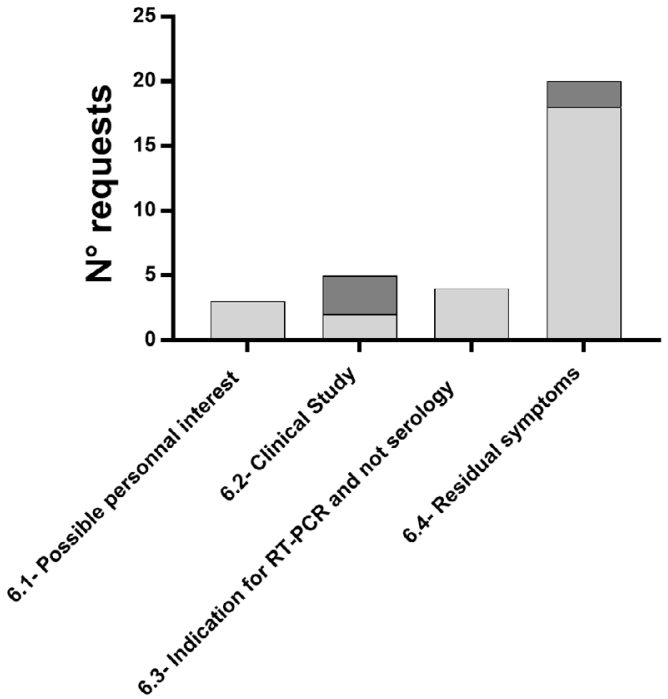

Figure 2. Repartition of the CHUV SARS-CoV-2 serology requests according clinical arguments

A medical doctor recorded a date of symptoms onset for 42 of them. We could thus determine that the time between symptoms onset and serology requests was between 4 to 61 days, with a mean at 27 days, and a median at 25 days. On the 313 CHUV patients, 241 (77\%) had a SARS-CoV-2 RT-PCR performed, including 46 (19\%) with a positive RT-PCRs. On average, the serology was requested 10.8 days after the RT-PCR. This period is longer for 43 patients with a positive serology (20.8 days on average), and shorter for the 198 patients with a negative serology ( 8.9 days on average), as expected. Based on these results, when initially negative, we now systematically recommend the repetition of the serology two weeks later, especially when the first serology is done $<15$ days after symptoms onset. Indeed, in our hands, the Epitope Diagnostics test reached $96 \%$ sensitivity on sera taken $\geq 15$ days after symptoms onset from hospitalized patients with mild to severe symptoms [4].

For the $354 \mathrm{CHUV}$ requests, an indication was determined from the electronic medical record of all patients except eight, and these indications, as well as their relative proportions and results are summarized in Figure 2. Clearly, the majority of the requests (49\%) concerned vulnerable patients (indication $\mathrm{N}^{\circ} 4$ ), regardless of their symptoms (Figure 2A). Among vulnerable patients, pregnant women represented about half of the requests $(52 \%)$, followed by oncological cases (37\%). Transplanted or other immunosuppressed patients represented only $8 \%$ and $3 \%$, respectively, of the vulnerable subjects (Figure 2B). The second most frequent indication was SARS symptoms with two consecutive negative SARS-CoV-2 RT-PCRs (indication $\mathrm{N}^{\circ} 1$ ), corresponding to $21 \%$ of the requests (Figure $2 \mathrm{~A}$ ). In third position are requests with either "specific clinical presentation" (indication $\mathrm{N}^{\circ} 5$ ) or "other type of indications" (indication $\mathrm{N}^{\circ} 6$; Figure 2). Among requests due to "specific clinical presentation", patients of dermatology with skin vasculitis or endothelitis, and patients with suspected GuillainBarré syndrome were the most frequent and represented $44 \%$ and $22 \%$ of these requests, respectively (Figure $2 \mathrm{C}$ ). Interestingly, among requests for "other type of indications" $\left(\mathrm{N}^{\circ} 6\right)$, patients with residuals symptoms but without RT-PCR or a negative RT-PCR performed at the acute phase of the disease (indication $\mathrm{N}^{\circ} 6.4$ ) represented $62.5 \%$ 
of this category, and 5\% of all 354 requests (Figure 2D). The residuals symptoms with no documented or negative RT-PCR (indication $\mathrm{N}^{\circ} 6.4$ ) appeared to be very important for patient care but was totally unexpected, since on $14^{\text {th }}$ April, when we started the SARS-CoV-2 serology, the occurrence of such post-infectious complications was not yet reported [5]. Today, such late complications appear to be common and typical of CoVID-19 [6-8].

One of the main limitations of this work is the short, studied period, which do not include possible much later onset complications, necessitating a serological investigation. Some of the indications that we expected such as (i) investigation of thrombo-embolic events, and (ii) investigations of chronic fatigue syndrome was not recorded, likely due to the relatively small number of subjects, the lack of information for most serologies requested by private practitioners and the early timing of this work, as compared to the outbreak reducing the number of cases with late complications. Thus, this work should be extended over the next 6 to 12 months.

Overall, this study demonstrates the good adequacy of serological requests with primary indications given by our authorities. Indeed, at least the in-hospital doctors largely complied with in-house guidelines and did not sent serology requests only for scientific interest or personal interest. This work may serve as a seed for identifications of clinical indications of SARS-CoV-2 serology for patients care.

\section{References}

1. Meyer B, Drosten C, Muller MA (2014) Serological assays for emerging coronaviruses: challenges and pitfalls. Virus Res 194: 175-183. [Crossref]

2. Zhang W, Du R-H, Li B, Zheng X-S, Yang X-L, et al. (2020) Molecular and serological investigation of 2019-nCoV infected patients: implication of multiple shedding routes. Emerg Microbes Infect 9: 386-389. [Crossref]

3. Caruana G, A Croxatto A, Coste AT, Opota O, Lamoth F, et al. (2020) Diagnostic strategies for SARS-CoV-2 infection and interpretation of microbiological results. Clin Microbiol Infect 26: 1178-1182. [Crossref]

4. Coste AT, Jaton K, Papadimitriou-Olivgeris M, Greub G, Croxatto A (2020) Comparison of SARS-CoV-2 serological tests with different antigen targets. J Clin Virol 134: 104690

5. Tang D, Comish P, Kang R (2020) Comish, and R. Kang, The hallmarks of COVID-19 disease. PLoS Pathog 16: e1008536. [Crossref]

6. Abboud H, Abboud FZ, Kharbouch H, Arkha Y, El Abbadi N, et al. (2020) COVID-19 and SARS-Cov-2 Infection: Pathophysiology and Clinical Effects on the Nervous System. World Neurosurg 140: 49-53. [Crossref]

7. Chen W, Li Z, Yang B, Wang P, Zhou Q, et al. (2020) Delayed-phase thrombocytopenia in patients with coronavirus disease 2019 (COVID-19). Br J Haematol 190: 179-184. [Crossref]

8. Pavon AG, Meier D, Samim D, Rotzinger DC, Fournier S, et al. (2020) First documentation of persistent SARS-CoV-2 infection presenting with late acute severe myocarditis. Can J Cardiol 36: 1326.e5-1326.e7. [Crossref]

Copyright: (C2020 Coste AT. This is an open-access article distributed under the terms of the Creative Commons Attribution License, which permits unrestricted use, distribution, and reproduction in any medium, provided the original author and source are credited. 